\title{
Thoracopagus conjoined twin: an unusual presentation
}

\author{
Rajesh Kumari*, Renu Arora, Nevadita Sarda, Jyotsna Suri, Pratima Mittal
}

Department of Obstetrics \& Gynecology, Safdarjung Hospital and VMMC, New Delhi, India

Received: 29 November 2013

Accepted: 15 December 2013

\author{
*Correspondence: \\ Dr. Rajesh Kumari, \\ E-mail: drrajeshkumari@yahoo.com
}

(C) 2014 Kumari $\mathrm{R}$ et al. This is an open-access article distributed under the terms of the Creative Commons Attribution Non-Commercial License, which permits unrestricted non-commercial use, distribution, and reproduction in any medium, provided the original work is properly cited.

\begin{abstract}
Conjoined twins are among rare clinical conditions observed by obstetricians. Due to rare incidence of this condition there is general lack of knowledge among obstetricians, especially at primary care level which leads to missed diagnosis during antenatal period. The management of this condition is complex especially in cases where the diagnosis is not known before onset of labour. A 30 - year old Hindu lady was referred to us from other hospital with diagnosis of twin pregnancy and prolonged second stage of labour. Clinical examination revealed findings of ruptured uterus and foetal head of one baby and feet of second baby were outside the introitus. Emergency laparotomy was done which revealed conjoined twins. This article report clinical course of a thoracopagus conjoined twin. The relevant literature is also reviewed.
\end{abstract}

Keywords: Conjoined twins, Laparotomy, Rupture uterus, Thoracopagus

\section{INTRODUCTION}

Conjoined twins are among rare clinical conditions observed by obstetricians across the world with estimated incidence varying from 1 in 50,000 to 100,000 births. $^{1-3}$ However, because of the complexity of the management it fascinates obstetricians. The etiology of conjoined twins is poorly understood. Two theories have been proposed - 1) fission theory which suggested that incomplete division of the embryonic disc from a single fertilized ovum between $15^{\text {th }}$ and $17^{\text {th }}$ day of gestation; and 2) fusion theory proposed secondary fusion of two originally separate monovular embryonic discs. ${ }^{4,5}$ Once formed, all conjoined twins may be further classified as diplopagus and heteropagus, based on their characteristics. Twins who are of approximately equal size and joined symmetrically are called as diplopagus conjoined twins. Whereas incases of heteropagus conjoined twins one member is normal or near normal (autosite) in size and other is incomplete (parasite) and is completely dependent on autosite.
Due to rare incidence of this condition there is general lack of knowledge among obstetricians, especially at primary care level. There is high probability of under estimation of the incidence because most of them end in aborting or still births without being reported. Here we report a case of thoracopagus conjoined twins delivered at our hospital.

\section{CASE REPORT}

A Gravida 3 Para 2 Live 2, 30-years Hindu female admitted in our labour room with prolonged second stage of labour. This was unsupervised pregnancy till onset of labour. Initially she went to a peripheral health centre with labour pains where she was diagnosed as a case of twin pregnancy. She was given trial for vaginal delivery and referred to us in second stage of labour as head failed to descend even after 4 hours. Her previous two pregnancies were uneventful vaginal delivery at home by traditional birth attendant. Both babies were normal and there was no family history of twin pregnancy, or ingestion of ovulation inducing agents. On general 
physical examination at the time of admission she was dehydrated, exhausted and moderately pale. She had fever $\left(38.2{ }^{0} \mathrm{C}\right)$, tachycardia (116 per minute), and hypotension $(90 / 50 \mathrm{mmHg})$. Her abdomen was overdistended, tender and normal uterine contour was absent. Vaginal examination revealed fetal head of one baby and feet of second baby were outside the introitus. A probable diagnosis of twin pregnancy with rupture uterus was made.

After adequate resuscitation she was taken up for emergency laparotomy. During laparotomy there was approximately $1250 \mathrm{ml}$ of blood in the peritoneal cavity. On further exploration, there was rupture of posterior wall of uterus extending upward to the fundus and downward in the lower uterine segment till vagina and broad ligament. Uterine cavity was opened anteriorly by incision on lower uterine segment. Both foetuses were joined at thorax and were dead. Decision for destructive surgery was taken and decapitation of first twin was done followed by extraction of foetuses through the incision at lower uterine segment. Placenta was monochorionic monoamniotic and umbilical cord was single (Figure 1). Both foetuses were male and combined weight of the babies was $4600 \mathrm{gms}$. Attendants refused for autopsy of the foetuses. Peroperative, patient required 2 units of blood and 2 units fresh frozen plasma. Due to irreparable ruptured uterus subtotal hysterectomy was done. Postoperative period was uneventful and she was discharged 14 days after surgery.

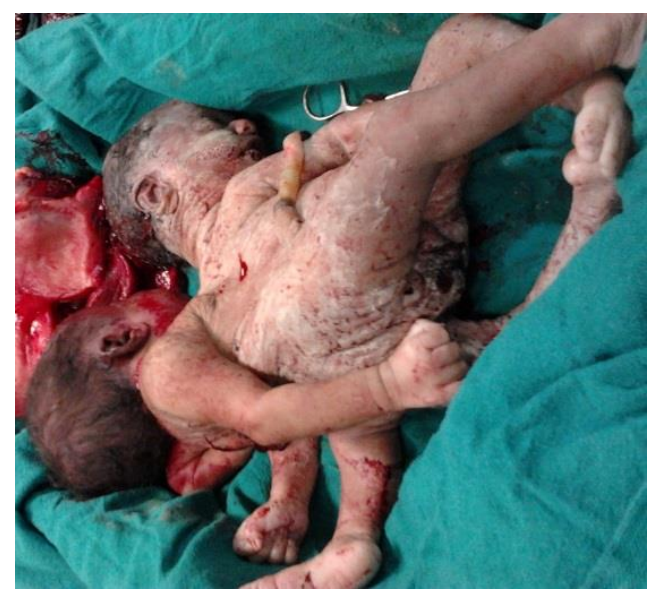

Figure 1: Showing monochorionic monoamniotic placenta and single umbilical cord in both foetuses.

\section{DISCUSSION}

Description of conjoined twins date back to ancient Egyptians but the first well documented case was born in 1100 in Kent, England. ${ }^{6}$ Based on the which part of the body is fixed conjoined twins may be grouped in the three major groups - twins with a ventral union which include cephalopagus (fixed at head), thoracopagus (fixed at chest), omphalopagus (fixed at umbilicus) and ischiopagus (fixed at hip), twins with a dorsal union pygopagus (fixed at sacrum), rachipagus (fixed at spine) and craniopagus (fixed at cranium) and twins with a lateral union - parapagus (fixed by side). ${ }^{7}$ Among reported cases of conjoined twins are thoracopagus, diplopagus and are predominantly females.

With availability ultrasonography (USG), diagnosis of twin pregnancy is usually not a major problem. However, the fact that they are conjoined is usually not determined until late in gestation or during parturition. ${ }^{8}$ If suspected the diagnosis can be made as early as 12 weeks of gestation. ${ }^{8}$ The suspicious features include inseparable foetal bodies and skin contours, unchanged relative positions of foetuses, both foetal head persistently at the same level, and a single umbilical cord containing more than three vessel. ${ }^{8}$ A detailed scanning at 20 weeks will define the extent of the conjoined area and area likely to be shared. ${ }^{8}$ Magnetic resonance imaging can provide more accurate anatomical details. ${ }^{8}$ The advantage of perinatal diagnosis is that, the time, place and mode of delivery can be planned. However just like this case many pregnancies are unsupervised without any antenatal check-up therefore early diagnosis is rarely possible, especially in developing countries.

Overall survival of conjoined twins is poor with high inutero $(28 \%)$ and early neonatal $(54 \%)$ death rate. Just like our case many times the management of labour is targeted to avoid associated complications. Vaginal delivery of conjoined twins at term is virtually impossible as obstruction is inevitable except premature or macerated feotus. ${ }^{9}$ Vaginal delivery of thoracophagus twins presenting as vertex at term has been reported. ${ }^{10}$ The described mechanism of labour in these cases was that one of the heads is born first while other occupied the space between the chin and chest of the first twin. The second head is then expelled with the help of traction of the first and the two bodies were then delivered simultaneously. ${ }^{10}$ Our case presented with ruptured uterus and head of one foetus and feet of the other twin outside introitus. Therefore she required laparotomy and destructive surgery for delivery of foetuses. Subtotal hysterectomy was also done due to irreparable rupture uterus.

\section{CONCLUSIONS}

Our case re-emphasizes the complexity of the conjoined twins. It also highlights how a missed or undiagnosed antenatal diagnosis of this condition may be a management challenge for the obstetrician and usually associated with morbidity. Therefore, everyone should be aware of this condition and twin pregnancies should be carefully screened for signs of conjoint foetus.

\section{Funding: No funding sources \\ Conflict of interest: None declared \\ Ethical approval: Not required}




\section{REFERENCES}

1. Kallen B, Rybo G. Conjoined twinning in Sweden. Acta Obstet Gynecol Scand. 1978;57(3):257-9.

2. Tang Y, Zhu J, Zhou GX, Dai L, Wang YP, Liang J. [An epidemiological study on conjoined twins in China, from 1996 to 2004]. Zhonghua Yu Fang Yi Xue Za Zhi. 2007 Jun;41(Suppl):146-9.

3. Tannuri AC, Batatinha JA, Velhote MC, Tannuri U. Conjoined twins: twenty years' experience at a reference center in Brazil. Clinics (Sao Paulo). 2013;68(3):371-7.

4. Spencer R. Theoretical and analytical embryology of conjoined twins: part I: embryogenesis. Clin Anat. 2000;13(1):36-53.

5. Spencer R. Theoretical and analytical embryology of conjoined twins: part II: adjustments to union. Clin Anat. 2000;13(2):97-120.
6. Guttmacher AF. Biographical notes on some famous conjoined twins (Birth defects original article series). Natl Found. 1967;3:10-7.

7. Spencer R. Anatomic description of conjoined twins: a plea for standardized terminology. J Pediatr Surg. 1996 Jul;31(7):941-4.

8. McHugh K, Kiely EM, Spitz L. Imaging of conjoined twins. Pediatr Radiol. 2006 Sep;36(9):899910; quiz 1002-3.

9. Agarwal U, Dahiya P, Khosla A. Vaginal birth of conjoined thoracopagus--a rare event. Arch Gynecol Obstet. 2003 Nov;269(1):66-7.

10. Shaw CC, Brumbaugh BB, Novey A. An anatomical and clinical study of a thoracopagus monster delivered alive at full time. Am J Obstet Gynaecol. 1934;27:655.

DOI: $10.5455 / 2320-1770 . i j r \operatorname{cog} 20140351$

Cite this article as: Kumari R, Arora R, Sarda S, Suri J, Mittal P. Thoracopagus conjoined twin: an unusual presentation. Int J Reprod Contracept Obstet Gynecol 2014;3:245-7. 